\title{
Familiarity Changes as a Function of Perceptual Shifts
}

\author{
Salvador Algarabel and Alfonso Pitarque \\ Universidad de Valencia (Spain)
}

This experiment compares the yes-no and forced recognition tests as methods of measuring familiarity. Participants faced a phase of 3 study-test recognition trials in which they studied words using all the letters of the alphabet (overlapping condition, $\mathrm{O}$ ), and an additional phase in which targets and lures did not share any letters (non-overlapping condition, NO). Finally, subjects performed a forced-choice task in which they had to choose one of two new words, each from one of the subsets (Parkin et al., 2001). Results in the NO condition were better than in the $\mathrm{O}$ condition in the yes-no recognition test, while the forced-choice rate was significantly higher than .50, showing their sensitivity to familiarity. When the letter set of the words for study in the third list of the NO condition was switched, the difference between NO and O conditions disappeared in yes-no test, while the force-choice rate was not higher than .50 . We conclude that both the yes-no test and the forced-choice test are valid and equivalent measures of familiarity under the right conditions.

Keywords: memory, recollection, familiarity.

Este experimento compara tareas de reconocimiento convencionales (sí-no) y de elección forzosa como métodos de medición de la familiaridad. Los participantes realizaron tres tareas de estudio y reconocimiento convencional en las que estudiaron y reconocieron palabras compuestas por todas las letras del alfabeto (condición de solapamiento, O) y otras tantas tareas similares en las que las palabras a estudiar y reconocer, y las palabras de relleno no compartían ninguna letra (condición de no solapamiento, NO). Tras este último bloque de tareas los sujetos realizaban una tarea de elección forzosa en la que tenían que elegir entre dos palabras nuevas, cada una formada por un subconjunto de letras distintas (Parkin et al., 2001). Los resultados en la condición NO fueron mejores que en la condición $\mathrm{O}$ en las tareas de reconocimiento sí-no, mientras que la tasa de elecciones forzosas a favor de las palabras formadas por el subconjunto de letras estudiadas fue significativamente superior a 0.50 , lo que muestra la sensibilidad de la tarea para medir familiaridad. Cuando en la tercera tarea de no solapamiento cambiamos sorpresivamente el conjunto de letras que formaban las palabras a estudiar y reconocer la diferencia entre las condiciones NO y O desapareció en la tarea de reconocimiento sí-no, mientras que la tasa de elección forzosa dejó de ser superior a 0.50 . Se concluye que tanto las tareas de reconocimiento convencional como de elección forzosa dan medidas equivalentes de estimación de la familiaridad bajo las condiciones adecuadas.

Palabras clave: memoria, reconocimiento, familiaridad.

This research was supported by Grant SEJ2007-60521 from The Spanish Ministerio de Ciencia y Tecnología (Dirección General de Investigación Científica y Técnica).

Correspondence concerning this article should be addressed to Salvador Algarabel. Facultad de Psicología. Universidad de Valencia. Blasco Ibanyez, 21. 46010 Valencia. (Spain). E-mail: Salvador.Algarabel@uv.es 
According to modern dual process theorists (Yonelinas, 2002), recognition is achieved through a combination of recollection and familiarity. This theory has taken shape as an alternative to the traditional single view, which explains recognition as the result of a single familiarity process. For dual process theorists, familiarity and recollection are defined in relation to each other (see Yonelinas, 2002). Familiarity is faster than recollection, has a different electrophysiological profile, is sustained by different brain substrates, and is affected differentially by a number of variables (see Yonelinas, 2002). Which of these two theories best explains recognition depends on the demonstration (or not) that the two processes exist independently; therefore, reliable measurement procedures are essential.

Familiarity, described as a sense of "déjà vu" without a context, is more difficult to measure experimentally than recollection (Paller, Voss, \& Boehm, 2007). While there are several experimental paradigms to estimate recollection (e.g. associative recognition; see Cohn \& Moscovitch, 2007), direct indices of familiarity are more enigmatic. Familiarity is induced when a procedure forces participants to forget the contextual information previously stored in memory or impedes its use during a test. High stimulus presentation rates or the induction of shallow levels of processing are forms of the first strategy, while imposing strict time response deadlines is an example of the second (see also Cleary \& Greene, 2005). Eventually, the feeling of familiarity is molecularly produced by a conjunction of similarities and differences among the stimuli and their status as old or new at test time (see for example, Nairne, 2002).

However, an extensively used procedure to estimate the weight of familiarity, particularly in neuropsychology (e.g. Westenberg, Paller, Holdstock, Mayes, \& Reber, 2006), is that which focuses on the contrast of responses in a yes-no versus a two-forced choice recognition test in which similar stimuli are presented in both (see Aggleton \& Shaw, 1996; Bastin \& Van der Linden, 2003). The implicit assumption is that the ability to recollect past information is of little use in a forced choice test, which obliges participants to use familiarity instead. However, a number of reports challenge this assumption. For example, Khoe, Kroll, Yonelinas, Dobbins, \& Knight (2000) and Yonelinas (2002) did not find differences in the use of recollection and familiarity across tasks, and Cook, Marsh, \& Hicks (2005) reported that the contributions of both processes were dependent on the characteristics of the stimuli. Despite these discrepancies, forced-choice is frequently employed to assess familiarity in healthy individuals and familiarity deficits in the elderly and those with neurological health problems associated with age (for example Westenberg et al., 2006). This methodology is useful for the experimental analysis of recognition memory and for the study of dementia in Alzheimer's disease. According to dual recognition theorists (Aggleton, \& Shaw, 1996), familiarity and recollection are sustained by different anatomical structures that are involved in the progression of Alzheimer's disease. In this way, the demonstration of deficits in familiarity may help to anticipate the time course of the disease.

In this paper, we intend to compare the virtues of the yesno and forced choice tests using a very simple manipulation aimed to induce familiarity (Algarabel, Pitarque, Tomás \& Mazón, 2010; Parkin, Ward, Squires, Furbear, Clark, \& Townshend, 2001). The task consists of a study phase of a series of words, with the particularity that they are formed from a restricted set of letters of the alphabet. During the test, the studied words are mixed for recognition with other words (distracters or lures) originating from the alternative set of letters (the non overlapping -NO- condition). When the responses in this condition are compared with those in a control condition (overlapping -O-) in which studied and non-studied words are formed from both letter sets, subjects unconsciously use the letter information to improve their recognition level. Provided that participants are unable to consciously report the use of the letters, the improvement is attributable to perceptual familiarity. When we name this familiarity "perceptual" we refer to the fact that its origin is not based on meaning. By "perceptual" we mean that the effect may well be achieved by a combination of orthographic and phonological features. We have carried out a series of experiments with this task (Algarabel et al., 2010; Algarabel, Escudero, et al., 2009; Algarabel, Rodríguez, et al., in press), showing that the familiarity effect is present even when recollection is completely absent, that it is equivalent during old and young age, and that it is absent in individuals with amnestic mild cognitive impairment and Alzheimer's disease patients.

However, as yet there are no data regarding the dependence of familiarity on type of recognition test. As previously indicated, neuropsychologists usually favor the two-alternative forced choice over the yes-no test because it reflects better the use of familiarity, though this tendency is based more on an assumption than experimental evidence. The goal of this experiment was to compare familiarity effects in a yes-no recognition task and a two-choice forced test (2FC) using the perceptual familiarity paradigm previously described.

A control group (no-switch condition) was exposed to three lists of words extracted from one letter set (NO condition), and three other lists using all the letters of the alphabet (O condition). The experimental group (switch condition) also studied the three lists of the $\mathrm{O}$ condition, and the first two lists of the NO condition, but the third list of the NO condition was changed by the alternative set of letters in order to observe the level of interference produced by the set switch. Following the NO phase, both groups were submitted to a forced choice test in which subjects had to choose between two new words each extracted from one of the two subsets of letters. There was a particularity here, as subjects were induced to believe that they had studied one of the two words of the $2 \mathrm{FC}$ test, although in fact they 
had not (because both words were new). We hypothesized that we would observe the familiarity use of the participants through the pattern of interference in the last yes-no test and in the $2 \mathrm{FC}$ test, and therefore demonstrate that the perceptual characteristics of the letters are the basis for the familiarity observed.

As deduced from a previous structural equation analysis (Algarabel et al., 2010), we expected participants to base their responses on a restricted number of letters. A single exposure to a study list is sufficient for this perceptual effect to appear. When faced with a new letter set in the third list, we did not expect interference in the number of hits as a result of dissimilarities. However, we did anticipate an increase in false alarms given that the "new" words in the third test were extracted from the same letter set as that of the first two lists, which would produce a false sensation of familiarity. With regard to the choice test, we anticipated a considerable decrease in performance in the switch condition with respect to the non-switch condition, as participants would have to choose between two "new" stimuli that would generate high levels of familiarity. In a choice trial, participants faced two highly familiar stimuli: one chosen from the letter set of the third list, and another selected from the letter set of the first two lists. An analysis of the differences in the responses under similar conditions in the yes-no recognition and the choice tests is vital in order to fully understand the procedure. Finally, we also intended to analyze the fate of the mirror effect (the pattern of data by which the condition producing higher hits also generates a lower number of false alarms than in the alternate condition). The existence of this mirror effect in the context of this experiment added another interesting variable (overlapping-non-overlapping letter set) to the arsenal of variables producing the effect on recognition memory, thereby endowing this experimental manipulation with further value as a testing ground for modern theories of recognition.

\section{Method}

\section{Participants}

42 University of Valencia (Spain) psychology students volunteered to participate in this study for a course credit, and were randomly assigned to one of the two between-subject conditions (switch or no-switch conditions). Participants who made any mention of using letter information in their responses were excluded from the analyses (1 from the noswitch condition and 1 from the switch condition).

\section{Materials}

The materials consisted of 392 Spanish words of between 3 and 9 letters selected from an initial database of 14,000 words. The NO condition included two sets of 98 words formed entirely from the following letters of the Spanish alphabet: a, e, u, b, d, g, j, n, r, z (set A), or i, o, c, f, h, l, m, $\tilde{\mathrm{n}}, \mathrm{p}, \mathrm{s}, \mathrm{t}, \mathrm{v}, \mathrm{y}$ (set B). These two sets were created through an iterative process by which we attempted to obtain two balanced sets of stimuli, particularly with regards to vowels. The remaining set (set C) contained words formed from the full alphabet, with the only criterion being that each word contained at least one letter from each of the two pools listed above. The three word sets were equated in mean frequency per two million (Alameda, \& Cuetos, 1995): $62.83(S D=188.57), 63.93(S D=201.30)$ and $60.02(S D=$ 130.46), respectively; and in length: $5.09(S D=1.34), 5.12$ $(S D=1.34), 4.90(S D=1.37)$, respectively.

\section{Design}

For each of the six yes-no recognition tasks stimuli were randomly divided into 6 lists of 26 words each (6 fillers), which constituted the targets, and were mixed with 6 other lists of distracters (or lures). This process was carried out independently for each subject. The target/distracter status of the letter sets was counterbalanced across subjects. The NO and O blocks were counterbalanced across subjects, with the forced choice categorization task always taking place after the NO block. Table 1 gives examples of these experimental manipulations.

In addition, 40 words ( 20 pairs) were employed for a forced choice categorization task: 20 from the target list (e.g. list A) and 20 from the distracter list (list B).

Type of list (O-NO) and list order (i.e. yes-no recognition tasks: first, second, or third) were within-subject variables while switch/no-switch conditions was a between subjects variable. Lists of the $\mathrm{O}$ conditions were the same in noswitch and switch conditions. The no-switch and switch conditions differed in that, in the former, the words from the three lists of the NO condition were formed from the same pool of letters, whereas in the latter, the words from the two first lists of the NO condition were formed from one set of letters but the target-distracter role was changed in the third list (i.e., if the stimuli studied in the first two lists were extracted from the set B, the study items for the third list were changed to those of the set A or vice versa; see table 1).

\section{Procedure}

Participants were assigned to groups of up to 10 and performed the tasks under computer control. They completed seven sequential tasks over a total duration of approximately 35 minutes. The overall design closely follows that described by Parkin et al. (2001) in their second experiment, with some modifications aimed at minimizing the possibility of using recollection. In both the $\mathrm{NO}$ and $\mathrm{O}$ conditions, participants underwent three study-test phases 
Table 1

Examples of stimuli from the three letter sets (sets A, B, and C) and design of the experiment for the switch/no-switch conditions (between subjects) and non-overlaping and overlaping conditions (NO/O; within-subjects)

\begin{tabular}{|c|c|c|}
\hline Set $A$ & Set $B$ & Set $C$ \\
\hline$a, e, u, b, d, g, j, n, r, z$ & $\mathrm{i}, \mathrm{o}, \mathrm{c}, \mathrm{f}, \mathrm{h}, \mathrm{l}, \mathrm{m}, \tilde{\mathrm{n}}, \mathrm{p}, \mathrm{s}, \mathrm{t}, \mathrm{v}, \mathrm{y}$ & $\begin{array}{l}\text { a, e, u, b, d, g, j, n, r, z, i, o, c, f, h, l, m, n, } \\
\text { p, s, t, v, y }\end{array}$ \\
\hline BREA, GARAJE, JARABE, ANDÉN & COLOSO, FILÓSOFO, OCHO, TÓPICO & CHALECO, GOTERA, TRAUMA, TELE \\
\hline Tasks & No-Switch condition & Switch condition \\
\hline $\begin{array}{l}\text { Recognition } 1,2 \& 3 \\
\text { List } 1,2 \& 3 \\
\text { (O condition) }\end{array}$ & $\begin{array}{l}\text { Study: set C } \\
\text { Test: targets (set C); lures (set C) }\end{array}$ & $\begin{array}{l}\text { Study: set C } \\
\text { Test: targets (set C); lures (set C) }\end{array}$ \\
\hline $\begin{array}{l}\text { Recognition } 4 \text { \& } 5 \\
\text { List } 1 \text { \& } 2 \\
\text { (NO condition) }\end{array}$ & $\begin{array}{l}\text { Study: set A } \\
\text { Test: targets (set A); lures (set B) }\end{array}$ & $\begin{array}{l}\text { Study: set A } \\
\text { Test: targets (set A); lures (set B) }\end{array}$ \\
\hline $\begin{array}{l}\text { Recognition } 6 \\
\text { List } 3 \\
\text { (NO condition) }\end{array}$ & $\begin{array}{l}\text { Study: set A } \\
\text { Test: targets (set A); lures (set B) }\end{array}$ & $\begin{array}{l}\text { Study: set B } \\
\text { Test: targets (set B); lures (set A) }\end{array}$ \\
\hline Forced choice task & set $A-\operatorname{set} B$ & set $A-\operatorname{set} B$ \\
\hline
\end{tabular}

of a standard recognition task. At study, 26 (of which 6 were fillers) words (size 18 font, in black on a white background) were visualized for $200 \mathrm{~ms}$ each. The speeded recognition test consisted of the random presentation of 20 studied words plus 20 distracters, which appeared individually on the computer screen. The participant had to make a "yes""no" judgment about the previous presentation of the word, using the " $\mathrm{d}$ " and " $\mathrm{k}$ " keys of the computer keyboard. If the response was produced after $1 \mathrm{sec}$. a message in red capital letters - "slow" - appeared on the screen for 750 ms. In addition, and with the purpose of promoting quick responses, participants were informed of the percentage of slow responses after each recognition test, and were encouraged to keep that percentage below $10 \%$.

The two-forced-choice task was always carried out after the NO condition. Participants were presented with a pair of words that appeared in the center of the screen. All these words were new and had not appeared in any of the previous study lists. Participants were requested to select the word that "could" have been presented previously. The words were visible until a response was given by the participant, pressing the " $v$ " (left choice) and "b" (right choice) keys of the keyboard. Words from each of the two subsets of letters were presented in the left and right position with equal frequency. Once they had completed the task, participants were asked to indicate the criteria they had used to respond, if aware of any.

\section{Results}

1.-Performance with the first two lists.

We first analyzed performance in the first two lists before the switch. A mixed ANOVA of the 2 lists (list $1 \&$ 2 ; within-subject variable) $\times 2$ letter set (NO, O; within- subject variable) x 2 groups (switch, no-switch; between subject-variable) on hits, false alarms and d' showed no effect of the list variable or of its interaction with the others (data satisfied the multivariate generalization of the Box's test for all the dependent variables). This preliminary analysis showed only the main effect of the letter set $(\mathrm{NO}, \mathrm{O})$ on hits, $F(1,38)=26.52, M S E=.02, p<.001$, $\eta_{\mathrm{p}}^{2}=.41$, false alarms, $F(1,38)=83.91, M S E=.01, p<$ $.001, \eta_{\mathrm{p}}^{2}=.69$, and $d^{\prime}, F(1,38)=70.57, M S E=.43, p<.001$, $\eta_{\mathrm{p}}^{2}=.65$, to be significant, indicating that familiarity had developed as a function of the continuous encounters with the restricted letter sets (see table 2). Thus, from that point on, we averaged lists $1 \& 2$ as just one list.

\section{2.-Performance with the switch list (third list).}

We then focused the analysis on the effect of the target condition (third list; data satisfied the Box's tests in all the later analysis). A mixed ANOVA on hits, with 2 groups (switch vs. no switch) as a between-subject variable, 2 conditions (NO vs. O) and 2 lists (list 1\&2 vs. 3) as withinsubject variables, showed the effect of condition to be significant, $F(1,38)=27.13, M S E=.01, p<.001, \eta_{\mathrm{p}}^{2}=$ .42 , and lists, $F(1,38)=12.48, M S E=.01, p<.001, \eta^{2}{ }_{p}^{p}=$ .25 , while the interaction of lists $\mathrm{x}$ groups was marginally significant (see Table 1), F (1,38) $=3.67, M S E=.01, p<$ $.07, \eta_{\mathrm{p}}^{2}=.09$.

The same ANOVA for false alarms indicated a significant interaction of conditions $\mathrm{x}$ lists $\mathrm{x}$ groups, $F(1,38)=5.99$, $M S E=.01, p<.05, \eta_{\mathrm{p}}^{2}=.14$, and a significant interaction of lists x groups (see table 1$), F(1,38)=10.03, M S E=.01$, $p<.01, \eta_{\mathrm{p}}^{2}=.21$. Bonferroni t tests comparing the means of the latter interaction revealed that the switch and no switch groups did not differ in false alarms in lists $1 \& 2, t$ $(38)<1$, but did in list $3, t(38)=2.78, p<.01$. The main 
Table 2

Proportion of hits, false alarms and d' (and standard errors) as a function of lists, experimental conditions (overlapping and non-overlapping: O-NO), and groups (Switch-No switch) in yes-no and forced-choice recognition tests

\begin{tabular}{|c|c|c|c|c|c|c|c|}
\hline \multirow[b]{3}{*}{ List } & \multicolumn{6}{|c|}{ Switch } & \multirow{3}{*}{$\begin{array}{l}\text { Forced } \\
\text { Choice }\end{array}$} \\
\hline & \multicolumn{2}{|c|}{ Hits } & \multicolumn{2}{|c|}{ FA } & \multicolumn{2}{|c|}{$\mathrm{d}^{\prime}$} & \\
\hline & NO & $\mathrm{O}$ & NO & $\mathrm{O}$ & NO & $\mathrm{O}$ & \\
\hline $1 \& 2$ & $.64(.04)$ & $\begin{array}{c}.56 \\
(.03)\end{array}$ & $\begin{array}{c}.19 \\
(.03)\end{array}$ & $\begin{array}{c}.35 \\
(.02)\end{array}$ & $\begin{array}{l}1.42 \\
(.17)\end{array}$ & $\begin{array}{c}.60 \\
(.09)\end{array}$ & $\begin{array}{c}.52 \\
(.11)\end{array}$ \\
\hline 3 & $\begin{array}{c}.55 \\
(.04)\end{array}$ & $\begin{array}{c}.49 \\
(.03)\end{array}$ & $\begin{array}{c}.29 \\
(.03)\end{array}$ & $\begin{array}{c}.33 \\
(.04)\end{array}$ & $\begin{array}{c}.87 \\
(.19)\end{array}$ & $\begin{array}{c}.47 \\
(.12)\end{array}$ & \\
\hline \multicolumn{8}{|c|}{ No-Switch } \\
\hline $1 \& 2$ & $\begin{array}{c}.66 \\
(.04)\end{array}$ & $\begin{array}{c}.53 \\
(.03)\end{array}$ & $\begin{array}{c}.17 \\
(.03)\end{array}$ & $\begin{array}{c}.32 \\
(.02)\end{array}$ & $\begin{array}{l}1.53 \\
(.17)\end{array}$ & $\begin{array}{c}.60 \\
(.09)\end{array}$ & .70 \\
\hline 3 & $\begin{array}{c}.63 \\
(.04)\end{array}$ & $\begin{array}{c}.51 \\
(.03)\end{array}$ & $\begin{array}{c}.11 \\
(.03)\end{array}$ & $\begin{array}{c}.28 \\
(.04)\end{array}$ & $\begin{array}{l}1.76 \\
(.19)\end{array}$ & $\begin{array}{c}.68 \\
(.12)\end{array}$ & (.13) \\
\hline
\end{tabular}

effects of conditions and groups were also significant, $F$ $(1,38)=68.11, M S E=.01, p<.001, \eta_{\mathrm{p}}^{2}=.64$, and $F(1,38)$ $=4.51, M S E=.05, p<.05, \eta_{\mathrm{p}}^{2}=.11$, respectively, while the interaction conditions $\mathrm{x}$ groups was marginally significant, $\mathrm{F}(1,38)=3.09, M S E=.01, p<.09, \eta_{\mathrm{p}}^{2}=.08$.

A similar pattern of results were found with respect to d'; the main effects of conditions and groups were significant, $F(1,38)=69.05, M S E=.38, p<.001, \eta^{2}=.65$, and $F$ $(1,38)=4.08, M S E=.88, p=.05, \eta_{\mathrm{p}}^{2}=.10$, respectively, as was the interaction of lists $\mathrm{x}$ groups (see table 1$), F(1,38)$ $=13.48, M S E=.18, p=.001, \eta_{p}^{2}=.26$. Bonferroni t tests over the means of this interaction showed that switch and no switch groups did not differ with respect to d' in lists $1 \& 2, t(38)<1$, but did in list $3, t(38)=3.23, p<.01$. The interactions of conditions $\mathrm{x}$ lists $\mathrm{x}$ groups, and conditions $\mathrm{x}$ groups were marginally significant, $F(1,38)=3.64, M S E=$ $.23, p<.07, \eta_{\mathrm{p}}^{2}=.09$, and $F(1,38)=3.99, M S E=.38, p<$ $.06, \eta_{\mathrm{p}}^{2}=.10$, respectively.

\section{3.-Performance in forced choice test}

We should point out again that the forced choice test consists of words that are new to the participant, although presented under the belief that one of them has been studied previously. Here, we analyze the percentage of choices of each letter set of study as a way of evaluating the basis of each participant's responses. A t-test showed significant differences in choice between the two groups after the switch, $t(38)=4.17, p<.01$. The preference of the noswitch group differed from $.50, t(19)=6.45, p<.01$, but not that of the switch group $t(19)<1$.

4.-Analysis of the mirror effect.

The mirror effect is a pattern of data in which the condition that produces higher hits also generates a lower number of false alarms than the alternate condition. In the control group a clear mirror effect appeared: two ANOVAs with 2 conditions (NO vs. O) x 2 lists (list $1 \& 2$ vs. 3) as within-subject variables showed that both independent variables did not interact neither on hits or false alarms, $F$ $(1,19)<1$ in both cases, which means that the differences between $\mathrm{NO}$ versus $\mathrm{O}$ were constant (see table 1) with respect to hits $(t(19)=3.98, p<.01, t(19)=3.17, p<.01$, in lists $1 \& 2$, and list 3 , respectively), and false alarms, $t$ (19) $=9.64, p<.01, t(19)=6.09, p<.01$, respectively.

\section{General Discussion}

Our experiment shows that perceptual familiarity - that is, the use of letter set information for improving recognition developed in only one exposure - is already present after the study of the first list. The same pattern of data was obtained in the choice test (no switch group), indicating that exposure to the study letter set created a bias in subjects by which they used these letters as the basis of their choice. This effect was manifested in an increase in hits and a decrease in false alarms. Additionally, the NO-O variable produced a mirror pattern, as is normally found with more traditionally studied variables, such as word frequency. Finally, the contrast between the $\mathrm{NO}$ and $\mathrm{O}$ conditions in the switch list and the results in the choice test in the same group indicates that both tasks are equally sensitive for detecting perceptual familiarity in this experimental situation. This is evidence in favor of the idea that the only source of responding used by participants is the perceptual information associated with the use of the different letter sets. Our results provide the first direct evidence that both tests act as indices of familiarity, and endorse the conclusions of Khoe et al (2000), who, implementing the remember-know procedure, reported that both tasks were equally sensitive 
to familiarity. That is, the forced choice results confirm previous assertions that participants relatively weigh up the two alternatives in terms of familiarity (see Aggleton \& Shaw, 1996; Bastin \& Van der Linden, 2003), though as demonstrated by the yes-no results, this is not an essential behavior. The conclusion that the forced-choice test is only sensitive to familiarity whereas the yes-no task is not (Westenberg et al., 2006) is unwarranted. However, in the context of the experimental task used in the present study, the former test is more convenient and simpler to use as an index of familiarity, provided that the experimental design does not make subjects suspicious about the non-studied status of the words.

The present data shed some light on theories regarding the mirror effect on recognition memory. With relation to this, it is important to point out that the experimental variable (NO-O) was manipulated across lists, and not within lists. In other words, the experimental manipulation created two classes of stimuli. Two types of mirror effects have been identified (Dobbins \& Kroll, 2005; Stretch \& Wixted, 1998) in the literature; those based on strength manipulations (type I), and those observed when classes of stimuli are manipulated (type II). The distinction is important because the mechanisms responsible for the two are different. Strength-based mirror is believed to be based on criterion shifts, whereas type II mirror may have a variety of causes (but see Dobbins \& Kroll, 2005). Based on the previously discussed characteristics of the current mirror effect, we defend the view that effect observed in the present study is type II (similar to the word frequency mirror) and not the strength type (type I), despite the fact that the experimental variable was not manipulated within lists (Stretch \& Wixted, 1998). Technically (DeCarlo, 2007), we consider that the reference distributions for the two experimental conditions can be scaled down to a common reference distribution, as is usually guaranteed when mixture lists are employed.

The classic signal detection approach to recognition assumes that participants respond on the basis of a criterion of a "strength-of-evidence" variable (familiarity) over which the distribution of old and new items overlap. Items producing a familiarity greater than the criterion receive "old" responses and are considered "new" if the familiarity produced is lower than the reference criterion. There are many variants of this explanation for the mirror pattern (see for example Dobbins \& Kroll, 2005; Stretch \& Wixted, 1998). One simple version indicates that the familiarity distribution of the studied non-overlapping words is shifted to the right of the overlapping word distribution studied. In the case of non-studied non-overlapping words, given that their component letters have not been studied, they are less familiar than those in the overlapping non-studied words. Therefore, the distribution of non-overlapping non-studied words is shifted to the left of the equivalent overlapping word distribution. Based on these assumptions, a classic "signal detection theory" explanation may be compatible with the current pattern of results. The mixture theory (DeCarlo, 2007), an extension of the classic signal detection approach, explains our results if we assume that the different words are obtained through a mixture of processing resources.

Some process theories of recognition require modifications if they are to explain the present mirror effect, as they usually attribute it to the simultaneous action of familiarity (false alarm differences) and recollection (hit differences) (Joordens \& Hockley, 2000). The activation confusion (SAC) model (Arndt \& Reder, 2003; Diana, Peterson, \& Reder, 2004; Reder, Donavos, \& Erickson, 2002; Reder, Paynter, Diana, Ngiam, \& Dickison, in press), for example, holds that knowledge is based on a network of interrelated concepts with activation levels that differ with respect to previous exposure. Each word has concept and specific context nodes. In the current experiments, all words in the $\mathrm{NO}$ and $\mathrm{O}$ conditions had previously been presented in a similar way. NO words were encoded by a more restricted number of letters (low letter fan) than $\mathrm{O}$ words (high letter fan). These letter sets define the "specific context" of each concept node of the words presented in the experiment. No other characteristics differentiate the words in the $\mathrm{O}$ condition from those in the $\mathrm{NO}$ condition. From the point of view of the SAC model, we can assume that the letters that formed the $\mathrm{NO}$ words influenced familiarity at the level of the specific context associated with each concept node. By definition, participants are unable to recollect this specific context, which limits its influence to an increased familiarity as a result of the episode node or the concept node itself. If this is the case, then familiarity alone is the only factor determining the differences between $\mathrm{NO}$ and $\mathrm{O}$ manipulations. Given the lack of previous exposure, the SAC does not explain the decrease in false alarms produced by the new words in the NO. Nonetheless, we can assume that there were more false alarms in the $\mathrm{O}$ condition because the letter set was shared by new and old words, and as a consequence, the activation of the targets increases the activation of the distracters. For this reason, these distracters produced a higher level of familiarity.

In conclusion, the yes-no and forced choice tests are equally valid indices of familiarity, at least in the context of the experimental task that we have used. Our results provide clues for the simplification of the current procedure in the context of neuropsychological research. Such a simplification could involve the presentation of a single list for study of words representing a set of letters, followed by a two-forced choice test. With an appropriate retention interval between study and test, subjects would not be capable of anticipating the purpose of the test, and a bias in their responses would, consequently, be avoided. This last point is of great importance for neuropsychological research in which patients with severe disabilities are often the subjects, and for whom quick and reliable procedures for assessing cognitive dimensions are essential. Finally, we would like to mention that the strength of this perceptual 
familiarity, demonstrated by the present experiment and other reports (Algarabel et al., 2009, 2010, in press), should be taken into account when performing experiments in which specific pools of stimuli are selected for specific purposes, in order to avoid the risk of introducing unwanted self-selected perceptual characteristics associated with the experimental stimuli. If care is not taken, the results of an experiment may be confused when the experimental manipulation is linked to the use of different sets of stimuli that vary in semantic, phonological or orthographic dimensions.

\section{References}

Alameda, J. R., \& Cuetos, F. (1995). Diccionario de frecuencias de las unidades linguísticas del castellano. [Frequency Dictionary of Castellan Linguistic units]. Oviedo, Spain: Universidad de Oviedo.

Algarabel, S., Pitarque, A., Tomás, J. M., \& Mazón, J. F. (2010). Explorations on familiarity produced by words having specific combinations of letters. The European Journal of Cognitive Psychology, 22, 265-285.

Algarabel, S., Escudero, J., Mazón, J. F., Pitarque, A., Peset, V., \& Lacruz, L. (2009) Familiarity based recognition in young, healthy aged people, mild cognitive impaired and Alzheimer's disease patients. Neuropsychologia, 47, 2056-2064.

Algarabel, S., Rodríguez, L. A., Escudero, J., Fuentes, M., Peset, V., Pitarque, A., et al. (in press). Recognition by familiarity in Parkinson's and Lewy-Body disease. Neuropsychologia.

Aggleton, J. P., \& Shaw, C. (1996). Amnesia and recognition memory: A re-analysis of psychometric data. Neuropsychologia, 34, 51-62.

Arndt, J., \& Reder, L. M. (2003). The effect of distinctive visual information on false recognition. Journal of Memory and Language, 48, 1-15.

Bastin, C., \& Van der Linden, M. (2003). The contribution of recollection and familiarity to recognition memory: A study of the effects of test format and aging. Neuropsychology, 17, 14-24.

Cleary, A. M., \& Greene, R. L. (2005). Recognition without perceptual identification: A measure of familiarity? The Quarterly Journal of Experimental Psychology, 58A, 11431152.

Cohn, M., \& Moscovitch, M. (2007). Dissociating measures of associative memory: Evidence and theoretical implications. Journal of Memory and Language, 57, 437-454.

Cook, G. I., Marsh, R. L., \& Hicks, J. L. (2005). Revisiting the role of recollection in item versus forced-choice recognition memory. Psychonomic Bulletin \& Review, 12, 720-725.
DeCarlo, L. T. (2007). The mirror effect and mixture signal detection theory. Journal of Experimental Psychology: Learning, Memory and Cognition, 33, 18-33.

Diana, R. A., Peterson, M. J., \& Reder, L. M. (2004). The role of spurious feature familiarity in recognition memory. Psychonomic Bulletin \& Review, 11, 150-156.

Dobbins, I. G., \& Kroll, N. E. A. (2005). Distinctiveness and the recognition mirror effect: Evidence for an item-based criterion placement heuristic. Journal of Experimental Psychology: Learning, Memory, and Cognition, 31, 1186-1198.

Joordens, S., \& Hockley, W. E. (2000). Recollection and familiarity through the looking glass: When old does not mirror new. Journal of Experimental Psychology: Learning, Memory, and Cognition, 26, 1534-1555.

Khoe, W., Kroll, N. E. A., Yonelinas, A. P., Dobbins, I. G., \& Knight, R. T. (2000). The contribution of recollection and familiarity to yes-no and forced-choice recognition tests in healthy subjects and amnesics. Neuropsychologia, 38, 1333-1341.

Nairne, J. S. (2002). The myth of the encoding-retrieval match. Memory, 10, 389-395.

Paller, K. A., Voss, J. L., \& Boehm, S. G. (2007). Validating neural correlates of familiarity. Trends in Cognitive Sciences, 11, 243-250.

Parkin, A. J., Ward, J., Squires, E. J., Furbear, H., Clark, A., \& Townshend, J. (2001). Data-driven recognition memory: A new technique and some data on age differences. Psychonomic Bulletin \& Review, 8, 812-819.

Reder, L. M., Donavos, D. K., \& Erickson, M. A. (2002). Perceptual match effects in direct tests of memory: The role of contextual fan. Memory \& Cognition, 30, 312-323.

Reder, L. M., Paynter, C., Diana, R. A., Ngiam, J., \& Dickison, D. (in press). Experience is a double-edged sword: A computational model of the encoding/retrieval tradeoff with familiarity. In B. Ross, \& A. S. Benjamin (Eds.), The psychology of learning and motivation. New York: Academic Press.

Stretch, V., \& Wixted, J. T. (1998). On the difference between strength-based and frequency-based mirror effects in recognition memory. Journal of Experimental Psychology: Learning, Memory, and Cognition, 24, 1379-1396.

Westerberg, C. E., Paller, K. E., Holdstock, J. S., Mayes, A. R., \& Reber, P. J. (2006). When memory does not fail: Familiaritybased recognition in mild cognitive impairment and Alzheimer's disease. Neuropsychology, 20, 193-205.

Yonelinas, A. P. (2002). The nature of recollection and familiarity: A review of 30 years of research. Journal of Memory and Language, 46, 441-517.

Received February 4, 2009 Revision received March 9, 2010 Accepted March 24, 2010 